\title{
Why Do Women with Breast Cancer Get Diagnosed and Treated Late in Sub-Saharan Africa? Perspectives from Women and Patients in Bamako, Mali
}

\author{
Kirstin Grosse Frie ${ }^{a}$ Hatouma Samoura ${ }^{b}$ Samba Diop ${ }^{b}$ Bakarou Kamate ${ }^{c}$ \\ Cheick Bougadari Traore ${ }^{c}$ Brahima Malle $^{c}$ Bourama Coulibaly ${ }^{c}$ Eva Johanna Kantelhardt ${ }^{a} d$ \\ ${ }^{a}$ Institute for Medical Epidemiology, Biostatistics and Informatics, Martin-Luther-University Halle-Wittenberg, Halle (Saale), Germany; \\ ${ }^{b}$ Institute of Public Health, University of Bamako, Bamako, Mali; \\ ${ }^{c}$ Institute of Pathology, University Hospital Point G, Bamako, Mali; \\ ${ }^{\mathrm{d}}$ Department of Gynecology, University Hospital Halle (Saale), Halle (Saale), Germany
}

\section{Keywords}

Breast cancer - Sub-Saharan Africa - Early detection . Delays · Patient pathway

\section{Summary}

Background: Breast cancer, the most common cancer among women worldwide, has a high mortality rate in low-income countries. In sub-Saharan Africa, most breast cancer patients are diagnosed with advanced disease. Some studies have quantified the time delay to diagnosis in sub-Saharan Africa, but very few have used qualitative methods to understand barriers leading to delay. This study analyses barriers throughout a breast cancer patient's pathway from symptom recognition to treatment in Mali. Method: Three focus group discussions were conducted. The model of pathways to treatment was used to structure the results into 4 time intervals: appraisal, help-seeking, diagnosis, and treatment, with a focus on barriers during each interval. Results: The main barriers during the appraisal interval were a low level of breast cancer knowledge among women, their families, and medical professionals, and during the help-seeking interval, mistrust in the community health care centers and economic hardship. Barriers during the diagnosis interval were low quality of health care services and lack of social support, and during the pretreatment interval high costs and lack of specialized services. Conclusion: Multilevel interventions are needed to ensure access, availability, and affordability of a minimum standard of care for breast cancer patients in sub-Saharan Africa.

(c) 2018 S. Karger GmbH, Freiburg

\section{Introduction}

Breast cancer is the most common cancer in women worldwide with 1.7 million new cases diagnosed in 2012, and the most frequent cause of cancer death in women accounting for 0.5 million deaths annually [1]. In Africa, breast cancer has become the most common cancer in terms of incidence and mortality, with 133,890 new cases and 63,160 deaths estimated in 2012 [1]. African women are affected by breast cancer during the childbearing years, almost a decade earlier than Caucasian women. This fact is probably related to genetic and demographic differences [2], has enormous additional negative effects on children and families, and represents a great economic and social burden for countries. Most of the patients in Africa are not diagnosed or treated early enough to fully benefit from treatment, and 30.3-100\% (depending on region) are diagnosed at a late stage with an average duration of symptoms of 8-12 months before diagnosis [3]. A median tumor size of $4.96 \mathrm{~cm}$ has been reported in a hospital cohort in Ethiopia [4]. Mammography screening programs are lacking for most African countries [5, 6], and there is an urgent need to develop affordable and adequate approaches for early detection and efficient treatment [7-10].

The study reported here is part of a larger research project on breast cancer in Mali. The latest data for Mali show - like in other African countries - an increase in the number of breast cancer cases with a high proportion of late-stage diagnoses, a high mortality rate, and an increasing burden among women of childbearing age [11]. Based on 203 women diagnosed with breast cancer during 1995-2004 in Mali, a very low survival of $16.6 \%$ was estimated (not age-standardized) in a global cancer surveillance study [12].

Two studies from Mali reported that 73 and 90\%, respectively, of breast cancer cases were diagnosed at a late stage (III and IV)

\section{KARGER}

() 2018 S. Karger GmbH, Freiburg 
$[13,14]$. To understand major barriers to early diagnosis and treatment, we used the model of pathway to treatment [15] recommended by the Aarhus statement [16] which is intended to improve the design and reporting of studies on delayed diagnosis. The model considers 5 important time points (symptom recognition, perceiving reason to seek health care, first medical consultation, diagnosis, and start of treatment) and 4 time intervals (appraisal, help-seeking, diagnosis, and treatment). The model has been used in several quantitative studies [15]. Only a number of studies have used qualitative methods to capture the patients' internal processes (individual perception and interpretation through social interaction) during the different time intervals [15]. Studies analyzing the pathway of women with breast [17-19] and cervical [20] cancer in sub-Saharan Africa were published only recently. Most studies are limited by the fact that they only include diagnosed patients.

\section{Material and Methods}

\section{Setting}

This study took place in Bamako, the capital of Mali in Western Africa. Bamako has about 1.8 million inhabitants [21] and is divided into 6 communities. Each community has between 4 and 12 community health care centers and a referral hospital with specialized services. For breast cancer care, there is one pathology, oncology, and radiology service in Bamako in the public sector and one oncology service in a private hospital. Breast cancer surgery is performed in several public and private hospitals, with a small number of services outside Bamako. Diagnosis of breast cancer is done by the pathologists at the only pathology service with fine needle aspiration. In rare cases, when tumors are very small, it is done by radiologists under ultrasound guidance. Core needle biopsy is limited to the private sector and not ultrasound-guided. Immunohistochemistry is only performed if samples are sent to other countries for analysis. The Malian Ministry of Health is subsidizing chemotherapy, but apart from this initiative, there is no financial support and no breast cancer prevention program in place.

\section{Data Collection}

To understand barriers that breast cancer patients in Mali face in relation to receiving (timely) diagnosis and treatment, we conducted focus group discussions. This qualitative method allowed us to gain insights into the perspectives of women and patients in Bamako. Between January and February 2016, we conducted one discussion with 8 breast cancer survivors at a local non-government organization, and two discussions - one with 12 and one with 5 (healthy) women - in 2 of the 6 communities in Bamako. Only women above 18 years of age were recruited; there were no further exclusion criteria. Permission from the local ethics committee of the Medical Faculty in Bamako, Mali was obtained.

All three discussions were conducted in the local language Bambara by a female Malian sociologist from the Institute of Public Health, University of Bamako. A discussion guide was developed and structured according to the 'Model of Pathway to Treatment' [15] in order to address the different time intervals between symptom recognition and start of treatment. The discussion guide for the breast cancer survivors focused on their patient history, while the discussions with women in the communities focused on possible (own or others') experiences with breast cancer and their general knowledge and ideas about the disease. Further questions were related to possible barriers to symptom recognition, health care seeking, diagnosis, and treatment. Before the discussions started, the sociologist explained the topic and asked for consent to participate in and record the discussion. Sociodemographic data (age, education, and marital status) was collected from all 25 participants. The discussion with the breast cancer survivors lasted about $120 \mathrm{~min}$, the discussion with 12 participants $90 \mathrm{~min}$, and that with 5 participants about $60 \mathrm{~min}$.

\section{Data Analysis}

The discussions were transcribed verbatim by the Malian sociologist into Bambara and then translated into French. Each participant was assigned an identification code to protect her identity. The investigator and the sociologist first read and structured the reported experiences of the former patients regarding the 4 time intervals: appraisal, help-seeking, diagnosis, and treatment. A thematic analysis was performed, and categories of barriers were developed. Then, the discussions with women in the communities were analyzed, and all barriers that could influence a woman along her patient pathway were coded and also grouped into categories. The constructed categories were matched with the 4 time intervals and compared with the categories developed from the discussion with the former patients.

\section{Results and Discussion}

All 8 former patients had finished their treatment between the last 1-14 years, had a mean age of 48 years (range 35-61 years), and were married; most had secondary education. In the first focus group with women from the communities, 12 women participated and had an average age of 42 years (range 20-65 years). All women were married, and half of them had no formal education, while the other half had primary or secondary education. In the second group with 5 participants, women had a mean age of 41 years (range 23-45 years) and were all married except for 1 (single); only 1 woman had received some formal education.

\section{Appraisal Interval: From Symptom Recognition to Perceiving a Reason to Seek Health Care}

Former patients reported that they had accidently noticed a lump in their breast, while none of the women had done breast self-examination. The discovery was often related to a sudden short pain in the breast or remembered precisely in relation with contemporaneous actions/events, e.g., while putting cream on the body, during prayer, while eating, or while breastfeeding.

- 'After work, I came back home and while eating my second spoon, suddenly, as we say, an ant bit me in my breast. I stood up and removed my clothes. And automatically I saw a lump which I had never noticed before.' (Patient 2)

- 'Once, I was breastfeeding, my child burped and the spots appeared.' (Patient 6)

Similar ideas about breast cancer were reported among the women in the communities. Especially breastfeeding or the contact with an item or insect were discussed as potential risk factors and were also reported elsewhere [21, 22]. Furthermore, the idea that somebody (often the second wife) put a spell on the women was reported.

- 'I was also told that putting a phone or money in the bra can provoke breast cancer in the long term. There are women who have small holes and we say it is an insect that has bitten them in the breast. They go to a traditional healer to remove the holes. We recognized that the traditional healers can remove the insects.' (Woman 2, Group 2)

Very few of the former patients brought the discovery of the symptom into relation with breast cancer. When we asked the women in the communities what they knew about breast cancer, all had heard about the disease but several said they did not know an- 
ything about it. 4 women reported having had an experience with breast cancer, and several reported known cases of 'breast cancer' in the family or neighborhood. However, very likely women were mixing up breast cancer with other breast illnesses, as symptoms described were quite atypical for breast cancer or might refer to very advanced cases.

- 'There are women who have infected breasts and we say there is a smell inside and finally it becomes a cancer.' (Woman 3, Group 1)

In relation to the interpretation of the symptoms, women in the community often said they would seek care from a traditional healer. This was only reported by 2 of the former patients, but several had heard of others that used traditional medicine.

Several former patients reported discussing and presenting symptoms to others, e.g., colleagues, other women in the family, husband, or persons with a medical background like nurses or pharmacists. Advice ranged from prompt health care seeking (rarely) to denial of the symptoms, advice to visit a traditional healer, or taking medicine.

- 'I started to be afraid. I showed it to many people, some said maybe you are approaching menopause, others said that it is nothing. After I saw two lumps appearing, without any pain but which were growing, I showed it to a pharmacist who called XXX. He told me it is a furuncle but taking antibiotics will prevent it from growing. I talked to my husband who said that I have nothing and that I talk too much.' (Patient 5)

Use of traditional medicine and low level of breast cancer knowledge among breast cancer patients [17-19, 23] have been reported in different studies from sub-Saharan Africa. Also, low breast cancer awareness among the general female population [24] and among female health care workers [25] were reported.

Help Seeking Interval: Perceiving a Reason to Discuss Symptoms with a Health Care Professional until First Consultation

Former patients had difficulties remembering precisely when they had perceived a reason to seek health care. For some, the detection of the bodily changes (rarely brought into association with breast cancer) made them seek medical advice immediately. Others sought medical advice when the symptom got worse or when they got a recommendation from another person. None reported difficulties seeking medical advice, while women in the communities highlighted that crowded health care centers with doctors who will not care for the poor and who have no time for a good diagnosis or prescribe medicine that does not work are reasons for them to stay at home or see a traditional healer. Also, fear related to the use of modern medicine or ignorance due to unawareness were reported as barriers.

- 'If you don't have the financial power, neither you nor your husband, they don't care for you, even if you cry; but if they know you have money, they give you attention. That's why I am using traditional medicine.' (Woman 5, Group 1)

Financial hardship $[18,22]$ and the possibility to easily access a health care practitioner [19] were reported elsewhere to influence immediate medical care among breast cancer patients in sub-Saharan Africa.

\section{Diagnostic Interval: From First Health Seeking to Diagnosis}

All former patients first visited referral or tertiary hospitals, both in the private and the public sector. One reported a wrong echography result and being diagnosed 2 years later. Almost half of the former patients were prescribed some medicine (cream, antibiotics) after first health care seeking and went back to the same doctor or another one when symptoms did not improve.

- 'I went to the Referral Hospital in XXX. They gave me drugs which I took for 3 months. During that period, I did not see any amelioration. I informed my husband. He told me to continue the treatment. 3 months later I went back to my doctor and he gave me other prescriptions for blood analyses. My sister did not want me to do the analyses and told me to go to the reference hospital in the commune XXX. After that consultation, they sent me to XXX and there they told me it is a cancer.' (Patient 7)

Women in the community highlighted their mistrust in health care workers: they have no knowledge nowadays, make wrong diagnoses, and often prescribe medicine that does not help. Other studies have also reported problems of wrong diagnosis and treatment $[18,19]$ among breast cancer patients in sub-Saharan Africa.

- 'I ask the health care workers to do good prescriptions. Often they give prescriptions that don't heal the illness.' (Woman 3, Group 2)

Former patients were sometimes diagnosed only by echography or mammography. Some were sent to the pathology service, or a biopsy was taken to confirm the diagnosis before any treatment was suggested. As there are no standardized procedures or guidelines on how to diagnose women with symptoms of breast cancer in Mali and the few specialized health care services for cancer diagnosis are scattered across Bamako, it is very likely that several women get lost along the complex pathway to diagnosis and go back to a traditional healer [26].

\section{Treatment Interval: From Diagnosis to Start of Treatment}

Patients reported most commonly that when they received their breast cancer diagnosis they thought they would die. They also reported that doctors supported them, gave them hope, and encouraged them to begin treatment.

- 'The first feeling is the sense of death. You don't want to live anymore.' (Patient 3)

The association of breast cancer with death was reported in several studies from sub-Saharan Africa $[18,27]$. It also clearly came up in the discussions with the women in the communities, but some women were aware that there are long-term survivors. Former patients also reported they often did not receive the social support they wanted from family members or others, because they did not know about breast cancer or only thought they would die.

- 'I told a brother-in-law at the blood bank and he wanted to know who told me that I had breast cancer. He told me this is not good news and automatically he gave me his absolutions and asked me if my family knows about it and to inform them.' (Patient 1)

Finally, most patients could find someone in the family who guided and supported them financially. Nevertheless, women were 
often advised by other family members to use traditional medicine. The necessity of strong social support by family members after diagnosis was also highlighted in a study among breast cancer survivors in Uganda [23].

- 'It was my sister and her husband who were informed and they did not want to tell me because I tend to overreact. They helped me to maintain morale and they paid all charges. Afterwards I told my husband. He told me that he has no money and that I should ask God for help and see a traditional healer. His younger brother also said someone has put a spell on me.' (Patient 5) Some patients first did not want to accept their diagnosis. Sometimes they found explanations as to why they could not have cancer. Others reported that they wanted to have treatment as soon as possible, but delays in getting treatment because of unavailability of doctors or drugs made them wait.

- 'It was in November when my illness started and they operated on me in September. Then my lump had already grown.' (Patient 4)

Many former patients chose treatment outside of Mali if they had enough financial support. Generally, financial hardship and problems with the availability of necessary treatment options were barriers to begin and continue treatment and were also reported in other studies from sub-Saharan Africa [19].

\section{Limitations}

This study provides insight into major barriers women in Bamako face with regard to receiving timely diagnosis and treatment after developing symptoms of breast cancer. However, more research is needed, since we analyzed only a small number of women and there might be further barriers, particularly for women living outside the capital city, Bamako. Furthermore, experiences and opinions of health care personnel and doctors should be researched which might balance the views of patients and women.

\section{Conclusion}

Main barriers during the appraisal interval were a low level of knowledge regarding breast cancer among women and the entire population, associated with several misconceptions and the preference for traditional medicine. During the help-seeking interval, ad- ditional barriers were dissatisfaction with medical doctors and mistrust in the health care system, as well as the expected financial burden of diagnosis and treatment. Barriers during the diagnosis interval were mainly the complexity and low quality of health care services, including the lack of guidelines for the detection and treatment of breast cancer patients. During the treatment interval, the main barriers were low social support, financial hardship, and lack of required treatment options. It becomes clear that most of these barriers are interrelated and that multilevel interventions are needed to address early diagnosis and treatment of breast cancer patients.

Broad health education and awareness campaigns might help to improve awareness and knowledge of breast cancer, but their sole effectiveness for early diagnosis and treatment has not been shown in intervention studies from sub-Saharan Africa. The identification and referral of symptomatic women also represents a challenge. Crowded community health care centers that are not staffed or set up to triage women with breast cancer, the limitations of diagnostic pathology, and limited access, high costs, and lack of guidelines with regard to breast cancer diagnosis and treatment must be considered first. We therefore must stress the fact that in order to improve early diagnosis, treatment, and survival of breast cancer patients in Mali and other sub-Saharan countries, prevention, diagnosis, and treatment options have to be made accessible, available, and affordable, including high quality and dignity of health care services for all breast cancer patients [28, 29].

In Africa, where health care systems are still struggling with high rates of infectious diseases and maternal and child mortality, the increase in non-communicable disease burdens is disproportionally high. For example, Mali is one of the countries with the highest rates of child and maternal deaths [30], while at the same time, its population is among those with the highest risk (26\%) of dying from a non-communicable disease before the age of 70 [31]. This demands urgent action on a national and international level to strengthen the health care systems in these countries. New global initiatives to improve women's health throughout the course of life were suggested as facilitators to address cancers in women [32].

\section{Disclosure Statement}

The authors declare no conflicts of interest.

\section{References}

1 Ferlay J, Soerjomataram I, Ervik M, Dikshit R, Eser S, Mathers C, Rebelo M, Parkin DM, Forman D, Bray F: GLOBOCAN 2012 vl.0, Cancer Incidence and Mortality Worldwide: IARC Cancer Base No. 11. Lyon, International Agency for Research on Cancer, 2013. globocan.iarc.fr (accessed 27/02/2017).

2 Brinton LA, Figueroa JD, Awuah B, Yarney J, Wiafe S, Wood SN, Ansong D, Nyarko K, Wiafe-Addai B, Clegg-Lamptey JN: Breast cancer in Sub-Saharan Africa: opportunities for prevention. Breast Cancer Res Treat 2014;144:467-478.

3 Jedy-Agba E, McCormack V, Adebamowo C, DosSantos-Silva I: Stage at diagnosis of breast cancer in sub-Saharan Africa: a systematic review and metaanalysis. Lancet Glob Health 2016;4:e923-e935.
4 Kantelhardt EJ, Zerche P, Mathewos A, Trocchi P, Addissie A, Aynalem A, Wondemagegnehu T, Ersumo T, Reeler A, Yonas B, Tinsae M, Gemechu T, Jemal A, Thomssen C, Stang A, Bogale S: Breast cancer survival in Ethiopia: a cohort study of 1,070 women. Int J Cancer 2014;135:702-709.

5 Corbex M, Burton R, Sancho-Garnier H: Breast cancer early detection methods for low and middle income countries, a review of the evidence. Breast 2012;21: 428-434.

6 Miller AB: Screening for breast cancer - is there an alternative to mammography? Asian Pac J Cancer Prev 2005;6:83-86, review.
7 El Saghir NS, Anderson BO: Breast cancer early detection and resources: where in the world do we start? Breast 2012;21:423-425

8 Grosse Frie K, Sefonias G, Muluken G, Tariku W, Traoré CB, Kamaté B, Mallé B, Vetter M, Krings A, Tamarat A, Addissie A, Mathewos A, Kantelhardt EJ: Update on female cancer in Africa: the AORTIC conference 2015, Morocco. Breast Care 2016;11:71-72.

9 Harford JB: Breast-cancer early detection in low-income and middle-income countries: do what you can versus one size fits all. Lancet Oncol 2011;12:306-312.

10 Kantelhardt EJ, Muluken G, Sefonias G, Wondimu A, Gebert HC, Unverzagt S, Addissie A: A review on breast cancer care in Africa. Breast Care 2015;10:364-370. 
11 Sighoko D, Kamaté B, Traore C, Mallé B, Coulibaly B, Karidiatou A, Diallo C, Bah E, McCormack V, Muwonge R, Bourgeois D, Gormally E, Curado MP, Bayo $S$, Hainaut P: Breast cancer in pre-menopausal women in West Africa: analysis of temporal trends and evaluation of risk factors associated with reproductive life. Breast 2013;22:828-835

12 Allemani C, Weir HK, Carreira H, et al.; CONCORD Working Group: Global surveillance of cancer survival 1995-2009: analysis of individual data for $25,676,887$ patients from 279 population-based registries in 67 countries (CONCORD-2). Lancet 2015;385:977-1010.

13 Ly M, Antoine M, Dembélé AK, Levy P, Rodenas A Touré BA, Badiaga Y, Dembélé BK, Bagayogo DC, Diallo YL, Koné AA, Callard P, Bernaudin JF, Diallo DA: High incidence of triple-negative tumors in sub-Saharan Africa: a prospective study of breast cancer characteristics and risk factors in Malian women seen in a Bamako university hospital. Oncology 2012;83:257-263.

14 Togo A, Traoré A, Traoré C, Dembélé BT, Kanté L, Diakité I, Maiga A, Traore SO, Coulibaly AC, Diallo G: Cancer du sein dans deux centres hospitaliers de Bamako (Mali): aspects diagnostiques et thérapeutiques (Breast cancer in Bamako hospitals: diagnostic and treatment). Journal Africain du Cancer 2010;2:88-91.

15 Walter F, Webster A, Scott S, Emery J: The Andersen Model of Total Patient Delay: a systematic review of its application in cancer diagnosis. J Health Serv Res Policy 2012;17:110-118.

16 Weller D, Vedsted P, Rubin G, Walter FM, Emery J, Scott S, Campbell C, Andersen RS, Hamilton W, Olesen F, Rose P, Nafees S, van Rijswijk E, Hiom S, Muth C, Beyer M, Neal RD: The Aarhus statement: improving design and reporting of studies on early cancer diagnosis. Br J Cancer 2012;106:1262-1267.
17 Kohler RE, Gopal S, Miller AR, Lee CN, Reeve BB, Weiner BJ, Wheeler SB: A framework for improving early detection of breast cancer in sub-Saharan Africa: a qualitative study of help-seeking behaviors among Malawian women. Patient Educ Couns 2017;100:167-173.

18 Moodley J, Cairncross L, Naiker T, Momberg M: Understanding pathways to breast cancer diagnosis among women in the Western Cape Province, South Africa: a qualitative study. BMJ Open 2016;6:e009905.

19 Pruitt L, Mumuni T, Raikhel E, Ademola A, Ogundiran T, Adenipekun A, Morhason-Bello I, Ojengbede OA, Olopade OI: Social barriers to diagnosis and treatment of breast cancer in patients presenting at a teaching hospital in Ibadan, Nigeria. Glob Public Health 2015;10:331-344.

20 Mwaka AD, Okello ES, Wabinga H, Walter FM: Symptomatic presentation with cervical cancer in Uganda: a qualitative study assessing the pathways to diagnosis in a low-income country. BMC Womens Health 2015;15:15.

21 UNStats 2009: unstats.un.org/unsd/Demographic/sources/ census/wphc/Mali/resultats.pdf (accessed 21/11/2016).

22 Asoogo C, Duma SE: Factors contributing to late breast cancer presentation for health care amongst women in Kumasi, Ghana. Curationis 2014;38.

23 Koon KP, Lehman CD, Gralow JR: The importance of survivors and partners in improving breast cancer outcomes in Uganda. Breast 2013;22:138-141.

24 Akhigbe AO, Omuemu VO: Knowledge, attitudes and practice of breast cancer screening among female health workers in a Nigerian urban city. BMC Cancer 2009;9:203.

25 Oladimeji KE, Tsoka-Gwegweni JM, Igbodekwe FC, Twomey M, Akolo C, Balarabe HS, Atilola O, Jegede $\mathrm{O}$, Oladimeji O: Knowledge and beliefs of breast selfexamination and breast cancer among market women in Ibadan, South West, Nigeria. PLoS One 2015;10: e0140904.
26 Dye TD, Bogale S, Hobden C, Tilahun Y, Hechter V, Deressa T, Bizé M, Reeler A: Complex care systems in developing countries: breast cancer patient navigation in Ethiopia. Cancer 2010;116:577-585.

27 Dye TD, Bogale S, Hobden C, Tilahun Y, Hechter V, Deressa T, Bize M, Reeler A: A mixed-method assessment of beliefs and practice around breast cancer in Ethiopia: implications for public health programming and cancer control. Glob Public Health 2011;6:719-731.

28 Elzawawy AM, Elbahaie AM, Dawood SM, Elbahaie HM, Badran A: Delay in seeking medical advice and late presentation of female breast cancer patients in most of the world. Could we make changes? The experience of 23 years in Port Said, Egypt. Breast Care 2008;3:37-41.

29 Unger-Saldaña K: Challenges to the early diagnosis and treatment of breast cancer in developing countries. World J Clin Oncol 2014;5:465-477.

30 You D, Hug L, Ejdemyr S, Idele P, Hogan D, Mathers C, Gerland P, New JR, Alkema L: Global, regional, and national levels and trends in under-5 mortality between 1990 and 2015, with scenario-based projections to 2030: a systematic analysis by the UN Inter-agency Group for Child Mortality Estimation. Lancet 2015; 386:2275-2286.

31 World Health Organization: Cancer Country Profiles 2014. www.who.int/nmh/countries/mli_en.pdf (accessed 27/02/2017).

32 Ginsburg O, Bray F, Coleman MP, et al: The global burden of women's cancers: a grand challenge in global health. Lancet 2016;389:847-860. 